\title{
PEMERANAN TOKOH RATU MAHRIT DALAM NASKAH RAJA MATI KARYA EUGÈNE IONESCO TERJEMAHAN IKRANAGARA
}

\author{
Gradhina Melya Amborowati \\ Institut Seni Indonesia Yogyakarta, Indonesia
}

\begin{abstract}
Abstrak: Raja Mati adalah salah satu naskah drama absurd karya Eugène Ionesco yang menceritakan tentang sebuah kerajaan yang sudah sekarat. Raja Mati memberikan pesan kepada kita bahwa hidup di dunia ini bersifat fana. Penelitian dan penciptaan seni ini hendak mengeksplorasi proses latihan dalam pemeranan tokoh Ratu Mahrit dalam naskah Raja Mati karya Eugène Ionesco. Tidak terdapat metode dan teori pemeranan spesifik untuk naskah absurd, sehingga penelitian dan penciptaan ini menggunakan proses kreatif Wallas (1926) sebagai panduan dalam eksplorasi pemeranan. Proses eksplorasi ini membawa peneliti pada pemahaman mengenai beragam absurditas dari berbagai sumber dan membuat beberapa metode latihan sendiri untuk melakukan pendekatan terhadap tokoh, terutama pada ketubuhan, vokal, dan rasa.
\end{abstract}

Kata kunci: Raja Mati, Absurd, Ionesco, Ratu Mahrit.

\begin{abstract}
Exit the King is one of the absurd playcripts by Eugène Ionesco which tells of a dying kingdom. Exit the King gives us a message that life in this world is perishable. This research and creation of art seeks to explore the process of training in the role of the Queen Mahrit in the Exit the King script by Eugène Ionesco. There are no specific methods and theories for the absurd play, so this research and creation of art uses the Wallas (1926) creative process as a guide in the role playing exploration. This exploration process brings the researchers to an understanding of the various absurdities from various sources and tries several methods of exercise to do the role, especially in body, vocal, and sense exploration.
\end{abstract}

Key word: Exit the King, Absurd, Ionesco, Queen Mahrit.

\section{Pendahuluan}

Kematian bukan hal yang asing terdengar di telinga semua orang. Kematian merupakan akhir dari kehidupan setiap makhluk di dunia. Hal tersebut menakutkan bagi sebagian orang. Rasa takut tidak akan bertemu lagi dengan keluarga dan kerabat atau rasa kehilangan bagi yang ditinggalkan. Kematian bisa datang kapan saja, karena usia, kecelakaan, bencana alam dan sebagainya.

Siap atau tidak siap pasti akan menghadapi kematian. Seperti halnya seseorang yang sakit keras dan didiagnosa akan meninggal dalam waktu tertentu.
Penolakan dan ketidakikhlasan pasti akan terjadi pada diri orang tersebut. Obat-obatan merupakan salah satu upaya untuk mengulur waktu. Begitu halnya dengan orang yang ditinggalkan, pasti belum siap untuk kehilangan.

Penulis pernah merasakan kehilangan seorang nenek, yang meninggal karena sakit. Padahal penulis sudah mengetahui pada akhirnya akan kehilangan nenek. Melihat nenek berjuang dalam melawan takdir kematiannya dengan alat-alat dokter. Sebelum itu nenek pernah berkata akan sembuh dan tidak akan meninggal sebelum melihat cucu-cucunya sukses. Tetapi, 
akhirnya sang nenek menyerah pada takdirnya. Keikhlasan merupakan hal yang sulit untuk dilakukan dalam menerima kematian nenek. Karena, tidak ada yang tahu datangnya kematian, untuk itu manusia harus menyiapkan diri untuk menerima dan kehilangan.

Ide tentang kematian merupakan hal menarik untuk dihadirkan dalam pementasan. Mengingat kematian akan dihadapi semua manusia. Pada naskah Raja Mati karya Eugène Ionesco, ditemukan kesamaan peristiwa. Raja Mati memiliki tema tentang kematian yang menceritakan tentang sebuah kerajaan yang sedang berada diambang keruntuhan. Seorang Raja bernama Bèrenger yang menolak takdir kematiannya. Ia memiliki dua istri, yakni Ratu Mahrit dan Ratu Mari. Raja Bèrenger selalu menolak bahwa ia akan mati, sehingga melakukan berbagai macam pembelaan untuk mengulur waktu kematiannya. Dalam hal ini, Ionesco mencoba menggambarkan keadaan absurditas manusia melalui naskah tersebut. Pemahaman terhadap usaha menyikapi kematian yang saling tumpang tindih sehingga membuat hal tersebut menjadi absurd.

Pada naskah Raja Mati karya Eugène Ionesco, terdapat kesamaan peristiwa. Selain itu, kekaguman pada ketegaran tokoh Ratu Mahrit untuk menerima dengan ikhlas dan menyadarkan suaminya tentang takdir kematiannya. Kesetiaan untuk menemaninya sampai pada akhir hayatnya walau ia telah diabaikan. Ketegasan dan kekejaman yang terdapat pada tokoh Ratu Mahrit sebagai sesuatu hal yang menarik untuk dimainkan. Karakter Ratu Mahrit sangat bertentangan dengan karakter penulis sehingga menjadi tantangan untuk memerankannya. Selama menjadi aktor, penulis selalu mendapatkan peran yang ceria dan atraktif. Selain itu, hal yang menjadi tantangan adalah bagaimana cara memerankan tokoh tersebut secara konsisten tanpa terpengaruh oleh emosi tokoh lainnya. Hal tersebut yang membuat penulis memilih naskah Raja Mati karya Eugène Ionesco.

Eugène Ionesco lahir di Slatina, Rumania, pada tanggal 26 November 1912. Ionesco banyak menulis naskah dan telah diterjemahkan dalam berbagai bahasa termasuk Indonesia. Beberapa naskahnya diilhami dari mimpi, masa kecil, dan imajinasinya. Ionesco menciptakan naskahnaskahnya bersumber dari ingatan di masa lalu, imajinasi liar, kecemasan, dan mimpimimpinya (Weiss, 2006). Lebih lanjut ia menjelaskan beberapa karyanya diilhami dari mimpi, seperti drama The Killer, Biduanita Botak (The Bald Soprano), dan Amadee (Weiss, 2006).

Namun, perlakuan berbeda terjadi pada penciptaan naskah Raja Mati. Dalam wawancaranya dengan Claude Benevoy, Ionesco menjelaskan bahwa proses menciptakan naskah Raja Mati tidak berawal dari mimpinya. Raja Mati bersumber dari kecemasan dirinya sendiri yang ketika itu sedang dilanda sakit keras hingga ia takut akan kematian (Bonnefoy, 1970).

Naskah Raja Mati merupakan karya ketiga dari 'Berenger Circle'. Seperti yang dijelaskan oleh Yudiaryani (2002), selama dua puluh tahun karya-karya Ionesco mengalami empat tahap perkembangan. Naskah Raja Mati berada di tahap ketiga yaitu karya-karya yang berstruktur konvensional dengan Bèrenger sebagai tokoh utama (Yudiariani, 2002). Naskahnaskah Ionesco merupakan perpaduan kompleks antara puisi, fantasi, mimpi buruk, maupun kritik sosial, dan budaya (Esslin, 2008). Ionesco mencoba menggambarkan keabsurdan kondisi manusia yang memberontak dan menunggu takdir. Hal itu merupakan ciri dari beberapa naskahnya. Seperti Rhinocéros, Kereta Kencana, dan Kursi-kursi. 
Eugène Ionesco mendefinisikan pemahamannya mengenai absurd, "absurd berarti tidak ada tujuan, tercabut dari akar relijius, metafisis maupun transendental, manusia tersesat, segala perilakunya menjadi tak bernalar, absurd, sia-sia" (Esslin, 2008). Wibowo (2018) menyatakan bahwa absurdisme adalah Gaya yang menyajikan satu lakon yang seolah tidak memiliki kaitan rasional antara peristiwa satu dengan yang lain, antara percakapan satu dengan yang lain. Lebih lanjut Wibowo menambahkan bahwa Unsur-unsur Surealisme dan Simbolisme digunakan bersamaan dengan irrasionalitas untuk memberikan sugesti ketidakbermaknaan hidup manusia serta kepelikan. Martin (2001) memberikan pandangan Albert Camus tentang absurd. Jawaban Camus terhadap yang absurd adalah pemberontakan. Manusia yang absurd adalah manusia yang mengerti absurditas itu, manusia yang tidak lari dari absurditas tetapi selalu menjaganya di dalam kesadarannya, inilah manusia menantang, inilah ia pemberontak.

Camus (1999) menjelaskan, absurd adalah sesuatu tindakan manusia yang secara sadar mengerti atas keabsurdan dirinya dan memberontak akan takdir hidupnya. Cara-cara yang dilakukan untuk menunjukan bahwa ia tidak seperti apa yang dikatakan oleh takdir terkadang diluar nalar dan bersifat sia-sia. Karena, memang pada dasarnya manusia tidak bisa melawan takdirnya.

Rumusan penciptaan yang terumuskan adalah sebagai berikut: Bagaimana memerankan karakter Ratu Mahrit dalam naskah Raja Mati karya Eugène Ionesco? Bagaimana proses yang dilakukan untuk memerankan tokoh Ratu Mahrit dalam naskah Raja Mati karya Eugène Ionesco?

Tujuan penciptaan tokoh Ratu Mahrit dalam naskah Raja Mati karya Eugène Ionesco adalah : Memerankan karakter Ratu
Mahrit dalam naskah Raja Mati karya Eugène Ionesco. Menemukan proses latihan untuk memerankan tokoh Ratu Mahrit dalam naskah Raja Mati karya Eugène Ionesco.

\section{Metode}

Metode merupakan cara teratur yang digunakan untuk melaksanakan suatu pekerjaan agar tercapai sesuai dengan yang dikehendaki, atau cara kerja yang bersistem untuk memudahkan pelaksanaan suatu kegiatan guna mencapai tujuan yang ditentukan. Masing-masing aktor memiliki metode dalam menciptakan peran di atas panggung. Wallas (lihat Damajanti, 2006) menjelaskan bahwa proses kreatif terdiri dari 4 tahap yakni, preparation, incubation, illumination, dan verification:

1. Preparation (tahap persiapan atau masukan), ialah tahap pengumpulan informasi atau data yang diperlukan untuk memecahkan suatu masalah. Langkah pengumpulan informasi atau data yakni, pemilihan naskah, analisis naskah, mencari tinjauan karya, dan persiapan latihan keaktoran.

2. Incubation (tahap pengeraman), ialah tahap ketika individu seakan-akan melepaskan diri untuk sementara dari masalah tersebut, dalam arti bahwa ia tidak memikirkan masalahnya secara sadar, tetapi "mengeraminya" dalam alam pra-sadar. Pada tahap ini penulis melakukan pengendapan tentang apa yang penulis dapatkan dari langkah Preparation.

3. Illumination (tahap ilham, inspirasi), ialah tahap timbulnya in-sight atau AhaErlebnis, saat timbulnya inspirasi atau gagasan baru, beserta proses-proses psikologis yang mengawali dan mengikuti munculnya inspirasi/gagasan baru. Pada tahap ini penulis melakukan perancangan dan pelatihan yang dilakukan untuk menerapkan gagasan baru yang lahir dari tahap sebelumnya, yakni proses latihan 
keaktoran yang nantinya akan melibatkan proses pelatihan untuk menemukan karakter dari tokoh Ratu Mahrit.

4. Verification (tahap pembuktian atau pengujian), disebut juga tahap evaluasi, ialah tahap ketika ide atau kreasi baru tersebut harus diuji terhadap realitas. Pada tahap ini, rancangan pembangunan tokoh Ratu Mahrit diuji dengan cara melakukan presentasi-presentasi untuk melihat perkembangan garapan. Tahap selanjutnya, akan dilaksanakan General Rehearsal dan tahap terakhir adalah pementasan Raja Mati karya Eugène Ionesco akan dilaksanakan sebagai proses akhir dari perancangan tokoh Ratu Mahrit agar bisa dinikmati oleh para penonton.

\section{Pembahasan}

Kehidupan dan alam semesta memiliki misteri masing-masing yang tidak kita tahu secara utuh. Kita hidup dari satu hari ke satu hari lainnya. Tanpa kita sadari, kita melakukan aktivitas yang hampir sama setiap harinya. Kehidupan yang kita jalani ini tidak lepas dari kematian. Semua makhluk yang bernyawa akan menemui takdir kematiannya masing-masing sebagaimana diungkapkan Camus (1999).

Semua kehidupan manusia beserta hasratnya yang hangat, aktivitasnya dengan pelbagai prestasi, semua keindahan yang telah ia berikan dan terima, semua akan berakhir dengan kematian. Setiap peristiwa dan setiap detik yang ia jalani semakin mendekatkannya pada kematian. Bayangbayang kematian bisa muncul melalui apa saja: ia adalah bagian dari semua kesenangan kita, ia tunjukan kesia-siaan dari semua aktivitas kita. Inilah perasaan absurd itu (Camus, 1999).

Bagi Camus, perasaan absurditas lebih merupakan sesuatu yang muncul dari pertemuan antara alam dan pikiran manusia (Martin, 2001). Terkadang manusia menyadari bahwa waktu berjalan dengan cepat dan menekan kita. Alam yang indah dan tertata, dibeberapa bagian tiba-tiba menjadi porak poranda. Aktivitas yang dilakukan seperti biasa, naik transportasi kendaraan untuk bepergian. Tetapi, tanpa diduga sebuah kejadian buruk menimpa. Kematian datang, penolakan atas perasaan kehilangan yang dialami. Terkadang muncul pertanyaan juga bertanya-tanya, untuk apa kehidupan diciptakan jika akan berujung pada kematian.

Dalam buku Jagat Teater dijelaskan bahwa Camus, melukiskan seorang tokoh bernama Sisifus, yang melakukan kegiatan aneh dengan mendorong sebongkah batu besar ke puncak bukit yang tidak pernah dicapainya. Setiap kali hampir mencapai puncaknya, batu itu terguling ke bawah, dan ia mengulanginya lagi terus-menerus (Soemanto, 2001). Hal tersebut menggambarkan kondisi kehidupan manusia saat ini, yang mengalami kesia-siaan. Manusia adalah makhluk absurd, dan cara menjalankan hidupnya pun dengan cara yang absurd (Yudiariani, 2000). Seperti yang dikatakan Camus pada essainya, yang disebut alasan untuk hidup sekaligus merupakan alasan untuk mati (Camus, 1999).

Kita hidup berdasarkan masa depan: "besok", "di kemudian hari", "bila kamu memperoleh kesempatan", "bila kamu cukup umur, kamu akan mengerti". Ketidakkonsekuenan ini mengagumkan, karena pada akhirnya masalahnya adalah mati (Camus, 1999). Kesia-siaan yang kita lakukan hanya menunggu datangnya waktu kematian. Terkadang terdapat penolakan disana, bahwa janganlah terlalu pasrah dengan kehidupan, bahwa kita mengesampingkan tentang kematian. Hidup seolah-olah kita abadi dan melupakan akan kematian.

Martin (2001) dalam bukunya Filsafat Eksistensialisme memaparkan tentang pandangan Camus terhadap manusia absurd:

"Manusia yang absurd adalah manusia yang mengerti arti absurditas itu, manusia yang tidak lari dari absurditas 
tetapi selalu menjaganya di dalam kesadarannya, inilah manusia yang menantang, inilah ia pemberontak. Ia berdiri menantang, ia berjuang tanpa harapan, ia tahu bahwa ia akan hancur, tetapi ia tetap melawan, ia ingin hidup dan tidak mau menyerah. Pemberontakan itu memberi nilai kehidupan, mengembalikan kebesaran pada eksistensi manusia."

Hal tersebut terdapat pada naskah Raja Mati karya Eugène Ionesco. Tentang pemberontakan akan takdir kehancuran dan kematian serta penyadaran akan absurditas untuk menyerahkan diri secara lengkap. Teater dan drama absurd adalah teater yang tidak mengetengahkan wilayah spiritual, tidak ada perbedaan benar atau salah tidak ada persoalan intelektual atau garis-garis petunjuk moral, dan lakon-lakonnya tidak dapat sebuah tragedi. Artinya, lakon-lakon absurd dapat menjadi penggambaran apa saja, bisa jadi pandangan penulis lakon terhadap dunia. Lakon-lakon absurd bersifat multitafsir. Teater absurd mewujudkan suasana yang menggambarkan eksistensi manusia, kehidupan, kematian, keadaan dunia yang tercabut dari realitas atau tanpa tujuan.

Esslin (2008) menjelaskan, bahwa teater absurd memproyeksikan dunia pribadi penulisnya, maka secara objektif tidak memiliki tokoh-tokoh yang valid. Wujud dari tokoh-tokoh tersebut dapat lahir dari interpretasi dalam memahami konsep absurditas serta pandangan penulis terhadap dunianya.

Teater absurd menghadapkan penonton pada tokoh-tokoh yang sulit identifikasi dan lakuannya atau kata-katanya sukar dipahami akan bersifat komik atau lucu dan menggelikan. Esslin (2008) mengatakan jika kecenderungan kita untuk melakukan identifikasi dihalangi dengan cara menciptakan tokoh yang aneh, maka kita akan menertawakan berbagai kesukaran yang dialami tokoh itu. Hal itu adalah yang disebut dengan efek komik yang nantinya akan dirasakan penonton sebagaimana dijelaskan Soemanto (2001).

"Situasi absurd dalam lakon absurd cenderung menuju puncak yang tidak bisa dijelaskan dengan kata-kata, suasana itu sendiri diharapkan menyergap pembaca dan penontonnya, tetapi juga mendorongnya ke belakang, sehingga terjadi jarak. Begitu penonton dan pembaca masuk ke dalam situasi, duka mendalam terjadi, begitu penonton kebelakang, tawa-getir muncul. Demikianlah suasana lucu dan duka terjalin."

Karena motif-motifnya tidak terpahami dan sifat lakuan tokoh-tokoh dalam teater absurd yang seringkali tidak dapat dijelaskan dan misterius secara efektif menghalangi identifikasi, maka teater semacam ini menjadi teater komik kendati sebenarnya persoalan yang diangkat menyedihkan, keras dan getir. Itulah sebabnya teater absurd memadukan kategori komedi dan tragedi, memadukan antara tawa dan kengerian. Hal tersebut terdapat pada naskah Raja Mati karya Eugène Ionesco pada saat upaya-upaya penyadaran dan pemberontakan terjadi.

\section{Konsep Pemeranan}

Untuk mewujudkan tokoh dalam sebuah pertunjukan, maka seorang aktor harus memiliki konsep pemeranan untuk tokoh yang akan dimainkan. Hal tersebut diperoleh dari analisis karakter menurut naskah dan interpretasi aktor. Seorang aktor yang baik adalah yang bisa menjelmakan perannya dengan hidup sekali. Artinya, seorang aktor harus bisa membuat pikiran, perasaan, watak, dan jasmaninya berubah untuk sementara, menjadi pikiran, perasaan, watak, dan jasmani peran yang ia mainkan.

Naskah Raja Mati karya Eugène Ionesco termasuk salah satu naskah absurd 
yang membicarakan tentang kematian. Adegan-adegan dan dialog-dialog pada naskah tersebut cenderung mengarah kepada sesuatu yang di luar logika. Teater absurd bermaksud membuat penontonnya sadar akan posisi manusia yang genting dan misterius di alam semesta ini (Esslin, 2008). Teater absurd bermaksud membuat penonton untuk berpikir kritis dan mengingatkan tentang dunia yang fana ini. Tokoh Ratu Mahrit adalah gambaran dari pikiran yang rasional dalam melihat kehidupan di dunia. Ia adalah seorang ratu yang tegas dalam menyampaikan segala pendapatnya. Ia berusaha menyadarkan raja agar menerima takdir kematiannya. Usahausaha yang dilakukan Ratu Mahrit dalam menyadarkan Raja menyebabkan terjadinya perdebatan dengan dialog-dialog dan adegan-adegan absurd yang tidak masuk akal.

Ratu Mahrit memiliki tubuh yang tegap, berjalan dengan langkah yang tenang, kepala menengadah ke atas yang menunjukan keangkuhan dan kewibawaannya sebagai seorang Ratu, tatapan mata tajam, bahasa tubuh yang tidak ragu-ragu, tegas, dewasa, dan berwibawa. Ratu Mahrit sangat peduli terhadap Raja sebagai suaminya, sehingga ia membantu Raja menghadapi kematiannya. Tokoh Ratu Mahrit akan merespon suasana-suasana absurd yang akan terjadi pada naskah secara over acting, tetapi tidak meninggalkan karakter utamanya.

\section{Proses Pemeranan}

Proses pemeranan seorang aktor agar mampu mewujudkan tokoh ke atas pentas, harus memiliki kesiapan jasmani dan rohani yang kuat dan sehat. Latihan dasar seni peran merupakan tahapan pertama dari proses pembentukan seorang aktor yang terdiri dari aktor dan dirinya, aktor dan lakon, dan proses membawakan peran (Anirun, 1998).
Latihan-latihan sifatnya praktikal, harus dibawakan di arena latihan melalui percobaan-percobaan, diskusi-diskusi, percobaan kembali dan penampilan (Awuy, 1999). Setiap aktor memiliki proses penciptaan yang berbeda-beda dalam memerankan seorang tokoh. Seorang aktor dituntut untuk memiliki kesiapan dari, tubuh, vokal, dan rasa. Karena, hal tersebut adalah modal dasar dan paling utama bagi seorang aktor (Anirun, 1998).

"Kita harus menelaah ada apa di dalam diri seorang aktor, sama saja seperti yang ada pada diri setiap orang, yaitu ada raga dan sukma. Dalam sukma kita terdapat unsur-unsur emosi, kemauan, semangat, pikiran, dan fantasi. Dalam raga ada tubuh, gerak, pernafasan, kekuatan. Maka, dalam menjalani latihan-latihan, sekalipun secara formal terdiri dari tiga macam, yakni olah tubuh, olah vokal, dan olah sukma, pada pelaksanaannya menjadi satu atau saling berkaitan antara satu dengan yang lainnya." (Awuy, 1999).

Adapun proses penciptaan yang dilakukan untuk memerankan tokoh Ratu Mahrit dalam naskah Raja Mati karya Eugène Ionesco, adalah mengolah tubuh, mengolah vokal, dan mengolah rasa. Untuk menuju kepada pikiran-pikiran absurd pada tokoh Ratu Mahrit, adapun usaha-usaha yang dilakukan oleh penulis, yaitu membaca tentang buku-buku absurd, mengunjungi rumah sakit, dan mengunjungi makam.

1. Mengolah Tubuh

Olah tubuh merupakan salah satu bentuk latihan dasar teknik pemeranan yang bertujuan membentuk tubuh aktor menjadi lentur sehingga aktor memiliki kesiapan dalam menggambarkan tokoh yang diperankannya (Iswantara, 2016). Latihanlatihan tubuh yang dilakukan seperti melatih ketahanan tubuh, melatih kelenturan tubuh dan juga stamina. Aktor dituntut untuk mempunyai kesiapan mental dan fisik.

2. Mengolah Vokal 
Kemampuan vokal yang baik bagi seorang aktor adalah syarat utama agar bisa memainkan peran secara proporsional (Saptaria, 2006). Vokal juga sebagai sarana menunjukan emosi seorang tokoh yang diperankan oleh aktor (Anirun, 1998).

"Pertama, suara sebagai perangkat ekspresi manusia umum. Kedua, suara sebagai perangkat ekspresi manusia pemeran (aktor). Sebagai perangkat ekspresi manusia pemeran suara telah bertambah fungsi dan takarannya, menjadi alat yang bisa dibentuk dan dimainkan, dalam rangka mewujudkan gambaran lengkap sosok peran."

Vokal seorang aktor harus selalu dilatih karena merupakan hal utama seorang aktor menyampaikan pesan melalui dialog. Dalam melakukan latihan vokal aktor dapat melakukan reading naskah. Reading actor dilakukan dengan dua tahapan, yaitu pertama, aktor membaca naskah secara acak atau tanpa penentuan tokoh terlebih dahulu. Kedua, aktor membaca dialog berdasarkan tokohnya dengan mulai mengisi emosi (Sumarno, 2017).

3. Mengolah Rasa

Melatih olah rasa sangat dibutuhkan bagi seorang aktor untuk mengatur emosi agar dapat dikeluarkan secara natural. Adapun beberapa pelatihan yang harus dilakukan untuk memperkuat sukma atau rasa seorang aktor, seperti latihan konsentrasi dan imajinasi.

Selain latihan-latihan dasar seorang aktor seperti olah tubuh, vokal, dan rasa. Adapun beberapa usaha untuk mencapai pemikiran-pemikiran absurd pada naskah dan tokoh dibutuhkan langkah-langkah yang akan dilakukan sebagai berikut.

Membaca tentang buku-buku absurd sangat dibutuhkan sebagai langkah awal dalam memahami definisi absurd. Setelah membaca buku-buku absurd barulah kita memahami tentang naskah dan penulisnya.
Kemudian, masuk pada tokoh dalam naskah absurd.

Pada suatu kesempatan penulis dapat berkunjung ke Rumah Sakit Bethesda di ruang $I C U$. Penulis melihat langsung ketika seseorang menghadapi sakaratul maut. Banyak alat-alat yang dipasang di tubuh mereka dan para keluarga yang mengelilingi sambil membacakan do'a. Ketika orang yang sekarat tersebut meninggal, penulis mendengar suara tangisan dan jeritan orang yang ditinggalkan. Ada rasa tidak rela dan berat untuk ditinggalkan.

Penulis juga pernah merasakan hal yang sama, kehilangan seorang nenek. Penulis yang sedang berada diluar kota tidak bisa menemani saat-saat terakhir dan hanya dikirimkan sebuah video yang selalu penulis putar sampai saat ini. Sampai muncul suatu pertanyaan pada diri penulis sendiri tentang kematian dan perpisahan yang harus ada. Perasaan tersebut yang dimaksud Camus (1999) sebagai perasaan absurd. Ketika seseorang sudah mengerti tentang adanya suatu takdir dan kemudian mempertanyakannya. Seperti yang sudah dijelaskan pada kutipan-kutipan sebelumnya mengenai absurditas dan kesadaran akan absurditas tersebut.

Berkunjung ke beberapa makam sebagai bentuk dari perenungan terhadap pengertian absurd dan melihat pada kehidupan nyata. Membuat diri sadar kembali bahwa di dalam kehidupan akan ada kematian. Semua manusia akan bermuara pada kematian dan akan dikubur di dalam tanah. Suatu ungkapan absurd yang sering didengar bahwa, 'yang dari tanah akan kembali ke tanah'. Kehidupan macam apa yang akan ditemui setelah kematian. Pertanyaan-pertanyaan selalu muncul di dalam pikiran penulis.

\section{Simpulan}

Setelah melewati banyak tahapan proses mulai dari pemilihan naskah, 
menentukan bentuk, menganalisis naskah dan tokoh, hingga menentukan para pendukung yang akan bekerjasama pada proses teater ini, maka terciptalah pertunjukan Raja Mati karya Eugène Ionesco atas kerjasama yang baik antara sutradara, aktor, penata setting panggung, penata rias, penata busana, penata lampu, dan tim produksi menjadi hal yang sangat penting dalam suksesnya suatu pementasan.

Naskah Raja Mati karya Eugène Ionesco adalah naskah yang dipilih oleh penulis, karena penulis memiliki peristiwa yang berhubungan dengan kematian. Naskah Raja Mati karya Eugène Ionesco merupakan salah satu naskah absurd yang membahas tentang kehidupan yang bersifat fana. Tokoh Ratu Mahrit merupakan tokoh yang dipilih oleh penulis untuk diperankan karena tokoh Ratu Mahrit sangat berbeda dari karakter penulis dan karena kekaguman akan pemikiran dari Ratu Mahrit. Hal itu merupakan tantangan bagi penulis dalam memainkan tokoh Ratu Mahrit. Tokoh Ratu Mahrit merupakan tokoh utama perempuan yang bertentangan dengan Raja. Ratu Mahrit adalah seorang Ratu utama di sebuah kerajaan antah berantah yang dipimpin oleh seorang Raja beristri dua. Ratu Mahrit selalu berpikir rasional dalam melihat kehidupan yang absurd di dunia ini. Kehidupan yang penuh dengan kesia-siaan dan akan berujung pada kematian.

Tokoh Ratu Mahrit dalam naskah Raja Mati memiliki karakter yang bertentangan terhadap penulis sehingga dibutuhkan metode dan latihan yang cukup keras untuk memerankan tokoh tersebut. Naskah Raja Mati karya Eugène Ionesco dipentaskan pada tanggal 16 Januari 2019, pukul 19.30 WIB di Gedung Auditorium Jurusan Teater Fakultas Seni Pertunjukan, Institut Seni Indonesia Yogyakarta. Tidaklah mudah dalam memainkan naskah absurd. Penulis harus membekali diri dengan memahami absurditas dari berbagai sumber dan penulis harus membuat beberapa metode latihan sendiri untuk melakukan pendekatan terhadap tokoh. Mengingat tidak ada metode dan teori pemeranan untuk naskah absurd. Selain pemahaman yang harus tajam dalam menginterpretasi sebuah naskah, hal-hal dasar harus diselesaikan terlebih dahulu seperti ketubuhan, vokal, dan rasa.

\section{Daftar Pustaka}

Anirun, Suyatna. (1998). Menjadi Aktor. Studiklub Teater Bandung bekerjasama dengan Taman Budaya Jawa Barat, dan PT Rekamedia Multiprakrsa. Bandung.

Bonnefoy, Claude. (1970). Conversation with Eugene Ionesco. London: Faber and Faber.

Camus, A. (1999). Mite Sisifus Pergulatan dengan Absurditas. Jakarta: Gramedia Pustaka Utama.

Damajanti, I. 2006. Psikologi Seni. Bandung: Kiblat Buku Utama.

Esslin, M. (2008). The Theatre of Absurd atau Teater Absurd, terjemahan Abdul Mukhid. Jawa Timur: Pustaka Banyumili.

Awuy, T.F. (1999). Teater Indonesia: Konsep, sejarah, problema. Jakarta: Dewan Kesenian Jakarta.

Iswantara, N. (2016). Drama, Teori, dan Praktik Seni Peran. Yogyakarta: Penerbit Media Kreativa.

Martin, V. (2001). Filsafat Eksistensialis. Yogyakarta: Pustaka Pelajar.

Saptaria, R. E. (2006). Panduan Praktis Akting Untuk Film dan Teater: Acting Handbook. Bandung: Rekayasa Sains Bandung.

Soemanto, B. (2001). Jagat Teater. Media Pressindo, Bekerjasama dengan Yayasan Adikarya IKAPI dan The Ford Foundation. Yogyakarta.

Sumarno, R. (2017). Karya Cipta Seni Pertunjukan: Metode 'Planting' Untuk Penyutradaraan Teater. Yogyakarta: Percetakan Galangpress. 
Weiss, J. (2006). Taruhan Mewujudkan Tulisan. Bandung: Jalasutra.

Wibowo, P.N.H. (2018). Modul pengembangan keprofesian berkelanjutan seni budaya seni teater SMA kelompok kompetensi h: pementasan teater. Direktorat Pembinaan Guru Pendidikan Dasar, Direktorat Jenderal Guru dan Tenaga Kependidikan, Jakarta

Yudiaryani. (2000). Ideologi Teater Modern Kita: Ideologi Teater Barat Memahami Realisme dan Futurisme Jaman. Yogyakarta: Pustaka Gondho Suli.

Yudiaryani. (2002). Panggung Teater Dunia, Perkembangan dan Perubahan Konvensi. Yogyakarta: Pustaka Gondho Suli. 